\section{KREATIF}

Jurnal Ilmiah

Prodi Manaiemen Universitas Pamulang
Pamulang ISSN : 2339 - 0689, E-ISSN : 2406-8616

J. KREATIF, Vol. 7, No. 2, Desember 2019 (Halaman 1-9)

Tersedia Online di : http://openjournal.unpam.ac.id/index.php/kreatif

\title{
PENGARUH GAYA KEPEMIMPINAN, KOMUNIKASI ORGANISASI DAN STRES KERJA TERHADAP TURNOVER INTENTION PADA PT PERTAMA LOGISTICS SERVICE
}

\author{
Irma Sari Octaviani \\ Program Studi Manajemen \\ Dosen Universitas Pamulang \\ dosen02479@unpam.ac.id
}

\begin{abstract}
ABSTRAK
Penelitian ini bertujuan untuk mengetahui dan menganalisis pengaruh gaya kepemimpinan, komunikasi organisasi dan stres kerja terhadap turnover intention pada PT Pertama Logistics Service baik secara parsial maupun secara simultan.

Metode penelitian yang digunakan dalam penelitian ini menggunakan metode Asosiatif, jumlah sampel yang diteliti sebanyak 107 responden, sedangkan alat pengumpulan data menggunakan kuesioner, adapun metode analisis data menggunakan regresi Linier Berganda.

Hasil penelitian menunjukan sebagai berikut: 1). Secara parsial gaya kepemimpinan bepengaruh negatif dan signifikan terhadap turnover intention pada PT. Pertama Logistics Service. 2). Secara parsial komunikasi organisasi bepengaruh negatif dan signifikan terhadap turnover intention pada PT Pertama Logistics Service. 3). Secara parsial stress kerja bepengaruh positif dan signifikan terhadap turnover intention pada PT Pertama Logistics Service. 4). Secara simultan gaya kepemimpinan, komunikasi organisasi, dan stress kerja berpengaruh positif dan signifikan terhadap turnover intention pada PT. Pertama Logistics Service.
\end{abstract}

Kata Kunci: gaya kepemimpinan, komunikasi organisasi, stres kerja, turnover intention

ABSTRACT
This study aims to determine and analyze the influence of leadership style, organizational communication and work stress on turnover intention at PT. The first Logistics Service is either partially or simultaneously.

The research method used in this study used the Associative method, the number of samples studied was 107 respondents, while the data collection tool used a questionnaire, as for the method of data analysis using Multiple Linear regression.

The results showed 1). Partially the leadership style has a negative and significant influence on turnover intention at PT. First Logistics Service. 2). Partially organizational communication has a negative and significant effect on turnover intention at PT. First Logistics Service. 3). Partially work stress has a positive and significant effect on turnover intention at PT. First Logistics Service. 4). Simultaneously leadership style, organizational communication, and work stress have a positive and significant effect on turnover intention at PT. First Logistics Service.

Keywords: leadership style, organizational communication, work stress, turnover intention 


\section{PENDAHULUAN}

\section{A. Latar Belakang}

Meningkatnya industri jasa pengiriman barang di Indonesia menyebabkan perusahaan berlomba-lomba meningkatkan pelayanan yang berkualitas demi memenuhi kebutuhan pelanggan. Bagi perusahaan jasa pengiriman barang maka hal yang perlu diperhatikan adalah dengan meningkatkan kualitas sumber daya manusianya terutama para karyawan yang bekerja. Demi menjaga agar perusahaan tetap menjadi pilihan utama pelanggannya maka para karyawan dituntut untuk selalu memberikan pelayanan yang terbaik, selalu cepat, tepat waktu serta dapat dipercaya oleh pelanggan.

Dengan semakin ketatnya persaingan bisnis yang terjadi menyebabkan target kerja menjadi bertambah sehingga munculnya adanya keinginan karyawan untuk meninggalkan organisasi pada PT Pertama Logistics Service yang berujung pada intensi keluarnya karyawan. Peningkatan turnover pada suatu perusahaan akan berdampak image yang negatif untuk perusahaan tersebut, karena dianggap kurang mampu memperhatikan kebutuhan karyawan khususnya. Hal ini menimbulkan pengeluaran biaya untuk seleksi calon karyawan yang harus disesuaikan dengan anggaran dan kebutuhan instansi terkait, pengaturan tenaga pengganti yang memerlukan waktu sehingga harus mengeluarkan biaya tambahan untuk memberi kompensasi bagi karyawan yang bekerja lembur, dan pekerjaan yang overloaded karena berkurangnya personil sehingga meningkatkan kemungkinan adanya human eror.

Banyak hal yang menjadi fokus perhatian dari pihak manajemen guna dapat menurunkan tingkat turn over karyawan, diantaranya adalah peran seorang dalam memimpin. Gaya kepemimpinan dapat diartikan sebagai perilaku atau tidakan ketika melakukan tugas manajemen dalam suatu organisasi. Efektivitas gaya kepemimpinan tidak ditentukan oleh satu atau berapa banyak manajer, tetapi merupakan hasil kolaborasi di antara semua anggota organisasi. Jika gaya manajemen digunakan dengan benar untuk mengelola karyawan yang ada, maka karyawan akan merasa nyaman dan termotivasi untuk bekerja secara optimal.

Selain itu salah satu penyebab turnover yang sering terjadi di PT Pertama Logistics Service yaitu kurangnya komunikasi antar karyawan sehingga menyebabkan rasa tidak nyaman pada karyawan yang bekerja karena kurangnya komunikasi untuk meningkatkan rasa kekeluargaan yang membuat lingkungan kerja menjadi semakin nyaman.

Munculnya keinginan seorang karyawan untuk meninggalkan perusahaan disebabkan pula oleh stres kerja. Stres kerja muncul dari banyaknya pekerjaan yang tidak dapat diselesaikan sesuai dengan waktu yang sudah ditentukan juga di iringi oleh beban kerja yang begitu besar, target terlalu tinggi, tekanan dari atasan juga dari pelanggan adalah gejala yang memicu stres kerja sehingga akan berdampak pada keinginan untuk keluar dari perusahaan. Fenomena yang penulis temui pada sebagian karyawan PT Pertama Logistics Service terutama pada bagian pengiriman barang adalah target pengiriman yang terlalu berat dikarenakan adanya sanksi yang harus mereka terima apabila 
pengiriman barang sampai telat dan tidak terkirim yaitu berupa pemotongan gaji bahkan Surat Peringatan (SP) hal ini yang memicu tingkat stres kerja tinggi yang mengakibatkan adanya keinginan untuk berpindah tempat dan mengundurkan diri.

Berdasarkan fenomena tersebut maka penelitian ini bermaksud untuk mengetahui apakah gaya kepemimpinan, komunikasi organisasi dan stres kerja memiliki pengaruh terhadap turnover intention baik secara individual maupun secara serempak.

\section{B. Rumusan Masalah}

Yang menjadi pertanyaan dalam permasalah ini ialah Penelitian ini bagaimana pengaruh gaya kepemimpinan, komunikasi organisasi dan stres kerja terhadap turnover intention pada PT Pertama Logistics Service baik secara parsial maupun secara simultan?

\section{TINJAUAN PUSTAKA}

\section{A. Gaya Kepemimpinan}

Menurut Thoha (2012:76), "gaya kepemimpinan adalah cara yang digunakan seorang manajer untuk mempengaruhi perilaku orang lain." Sementara itu menurut Sunarcaya (2008:87), "gaya kepemimpinan merupakan suatu cara yang dilakukan oleh atasan dalam mengendalikan bawahan untuk melakukan sesuatu". Dari uraian tersebut tentang Gaya Kepemimpinan, penulis menyimpulkan hal dan bersumber dari Terry (2007:88-94) yang bisa dijadikan indikator Gaya Kepemimpinan seorang pegawai sebagai berikut : Keteladanan, Komunikasi, Penguasaan prosedur kerja, Pengetahuan manajerial.

\section{B. Komunikasi Organisasi}

Menurut Mangkunegara (2013:128), "komunikasi adalah proses mentransfer informasi, ide, pemahaman dari satu orang ke orang lain, yang dapat ditafsirkan untuk tujuan yang dimaksudkan". Maka indikatorindikator komunikasi antara lain adalah: Kemudahan dalam memperoleh informasi, Insensitas komunikasi, Evektivitas komunikasi, Tingkat pemahaman pesan dan Perubahan sikap.

\section{Stres Kerja}

Menurut Hasibuan (2012:87), "stres adalah keadaan ketegangan yang memengaruhi emosi, proses berpikir, dan keadaan seseorang". Hasibuan (2012:204) menyatakan bahwa indikator stres kerja antara lain: Beban kerja yang sulit dan berlebihan, Tekanan dan sikap pimpinan yang kurang adil dan wajar, Waktu dan peralatan keja yang kurang memadai, Konflik antara pribadi dengan pimpinan atau kelompok kerja serta Balas jasa yang terlalu rendah.

\section{Turnover Intention}

Menurut Rivai (2014: 30), "turnover adalah kesediaan karyawan untuk secara sukarela meninggalkan perusahaan sesuai pilihan mereka". Suwandi (2011:31) menyatakan bahwa indikator turnover adalah: Keinginan mencari lowongan, mengevaluasi kemungkinan menemukan pekerjaan yang layak ditempat lain dan meninggalkan Organisasi. 


\section{E. Kerangka Pemikiran}

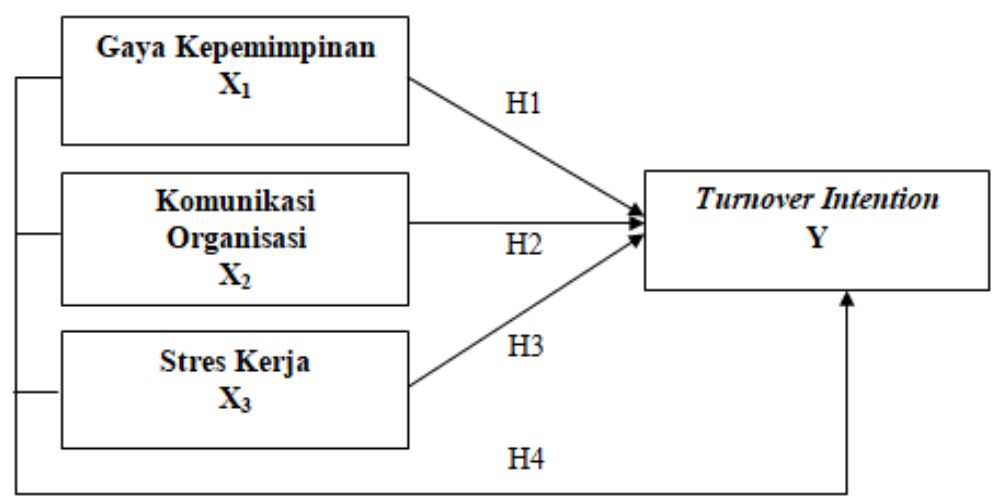

Gambar 1.

Kerangka Berfikir

\section{F. Hipotesis}

Diduga Gaya kepemimpinan, komunikasi organisasi, dan stres kerja berpengaruh signifikan terhadap kinerja karyawan baik secara parsial maupun secara simultan.

\section{METODOLOGI PENELITIAN}

\section{A. Tempat Penelitian}

Perusahaan yang menjadi objek peneliti ini adalah PT Pertama Logistics Service yang beralamat di Jl. Trocadero No 107 Palaise de Europe Lippo Karawaci Tangerang.

\section{B. Metode Penelitian}

Metode yang digunakan adalah asosiatif, menurut Sugiyono (2015:44), "metode asosiatif adalah metode penelitian yang dirancang untuk mengetahui pengaruh atau hubungan antara dua variabel lainnya".

\section{Populasi dan Sampel}

Untuk sampel dalam penelitian ini menggunakan sampling jenuh yaitu jumlah keseluruhan karyawan pada PT Pertama Logistics Service sebanyak 107 orang.

\section{Metode Analisis Data}

Metode analisis data yang digunakan yaitu : uji validitas, uji reliabilitas, uji asumsi klasik, regresi linier berganda, koefisien determinasi dan pengujian hipotesis.

\section{HASIL PENELITIAN}

\section{A. Hasil Uji Validitas dan Reliabilitas}

\section{Tabel}

Uji Validitas 


\begin{tabular}{|c|c|c|c|c|c|c|}
\hline Pernyataan & $\begin{array}{c}\text { Nilai r } \\
\text { hitung } \\
\text { Variabel } \\
\left(\mathbf{X}_{\mathbf{1}}\right)\end{array}$ & $\begin{array}{c}\text { Nilai r } \\
\text { bitung } \\
\text { Variabel } \\
\left(\mathbf{X}_{\mathbf{2}}\right)\end{array}$ & $\begin{array}{c}\text { Nilai r } \\
\text { hitung } \\
\text { Variabel } \\
\left(\mathbf{X}_{\mathbf{3}}\right)\end{array}$ & $\begin{array}{c}\text { Nilai r } \\
\text { hitung } \\
\text { Variabel } \\
(\mathbf{Y})\end{array}$ & $\begin{array}{c}\text { Nilai } \\
\mathbf{r}_{\text {tabel }}\end{array}$ & Keterangan \\
\hline Pernyataan 1 & 0,634 & 0,691 & 0,906 & 0,673 & 0,1909 & Valid \\
\hline Pernyataan 2 & 0,483 & 0,533 & 0,924 & 0,701 & 0,1909 & Valid \\
\hline Pernyataan 3 & 0,610 & 0,664 & 0,927 & 0,788 & 0,1909 & Valid \\
\hline Pernyataan 4 & 0,654 & 0,621 & 0,663 & 0,683 & 0,1909 & Valid \\
\hline Pernyataan 5 & 0,547 & 0,827 & 0,945 & 0,798 & 0,1909 & Valid \\
\hline Pernyataan 6 & 0,768 & 0,797 & 0,896 & 0,400 & 0,1909 & Valid \\
\hline Pernyataan 7 & 0,714 & 0,738 & 0,907 & 0,678 & 0,1909 & Valid \\
\hline Pernyataan 8 & 0,648 & 0,464 & 0,689 & 0,798 & 0,1909 & Valid \\
\hline Pernyataan 9 & 0,550 & 0,802 & 0,902 & 0,795 & 0,1909 & Valid \\
\hline Pernyataan 10 & 0,492 & 0,423 & 0,920 & 0,756 & 0,1909 & Valid \\
\hline
\end{tabular}

Sumber: SPSS V 22

Tabel tersebut menunjukan keseluruhan nilai $r_{\text {hitung }}$ berada diatas nilai $r_{\text {tabel }}$ dengan demikian seluruh item kuesioner adalah valid.

Tabel

Uji Reliabilitas

\begin{tabular}{|l|c|}
\hline \multicolumn{1}{|c|}{ Variabel } & Nilai Cronbach Alpha \\
\hline Gaya Kepemimpinan $\left(\mathrm{X}_{1}\right)$ & 0,810 \\
\hline Komunikasi $\left(\mathrm{X}_{2}\right)$ & 0,856 \\
\hline Stres Kerja $\left(\mathrm{X}_{3}\right)$ & 0,964 \\
\hline Turnover Intention $(\mathrm{Y})$ & 0,887 \\
\hline
\end{tabular}

Sumber: SPSS V 22

Nilai keseluruhan variabel berada diatas nilai kritis sebesar 0,60 oleh karena itu semua jawaban responden adalah reliabel.

\section{B. Hasil Uji Asumsi Klasik}

\section{Uji Normalitas Data}

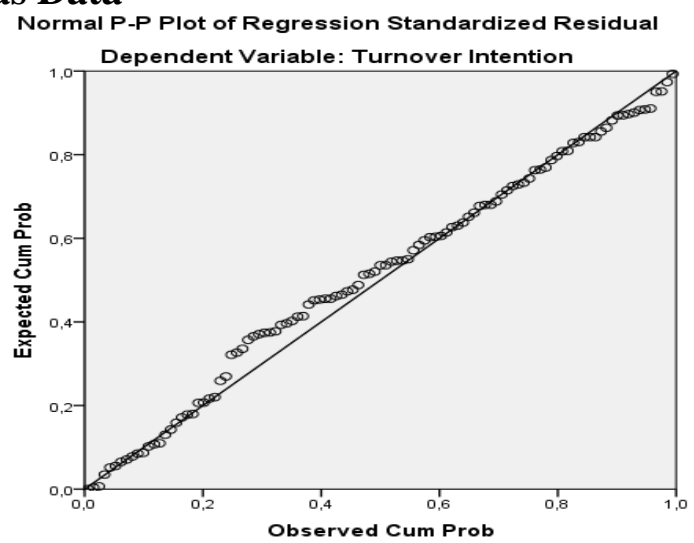

Sumber : SPSS 22

Gambar 2

\section{Normalitas Data}

Melihat tampilan grafik tersebut menunjukan asumsi normalitas terpenuhi karena penyebaran data yang mengikuti garis diagonal. 


\section{Uji Multikolineritas}

\section{Tabel}

Uji Multikolineritas

\begin{tabular}{|c|c|c|c|}
\hline \multirow{2}{*}{\multicolumn{2}{|c|}{ Model }} & \multicolumn{2}{|c|}{ Collinearity Statistics } \\
\hline & & Tolerance & VIF \\
\hline \multirow[t]{4}{*}{1} & (Constant) & & \\
\hline & Gaya Kepemimpinan &, 630 & 1,586 \\
\hline & Komunikasi &, 638 & 1,568 \\
\hline & Stres Kerja & ,963 & 1,038 \\
\hline
\end{tabular}

a. Dependent Variable: Turnover Intention Sumber: SPSS V 22

Nilai tolerance keseluruhan variabel lebih besar $>0,10$, VIF keseluruhan variabel lebih kecil $<10$ sehingga dinyatakan gejala multikolinieritas tidak terjadi.

\section{Uji Heteroskedastisitas}

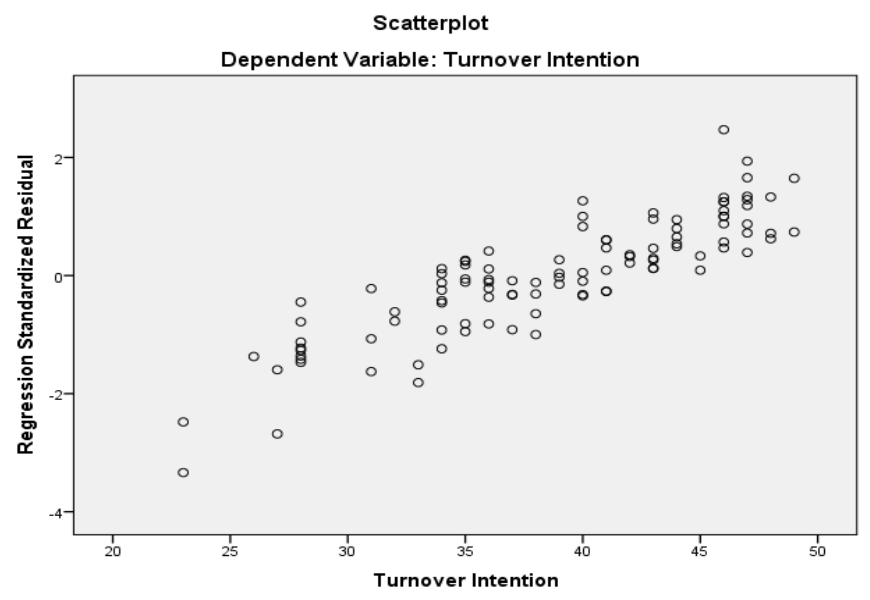

Sumber : SPSS 22

Gambar 3

Heteroskedastisitas

Dari grafik, kita melihat penyebaran data yang menyebar secara acak dan tidak membentuk pola tertentu, sehingga gejala heteroskedastisitas tidak terjadi.

\section{Hasil Regresi Linier Berganda dan Hipotesis Parsial \\ Tabel}

\section{Regresi Linier Berganda}

\begin{tabular}{|l|l|r|r|r|r|r|}
\hline \multicolumn{2}{|c|}{ Model } & \multicolumn{2}{|c|}{$\begin{array}{c}\text { Unstandardized } \\
\text { Coefficients }\end{array}$} & $\begin{array}{c}\text { Standardized } \\
\text { Coefficients }\end{array}$ & \multirow{2}{*}{$\mathrm{t}$} & \multirow{2}{*}{ Sig. } \\
\cline { 3 - 6 } \multicolumn{2}{|c|}{} & \multicolumn{1}{|c|}{ B } & Std. Error & Beta & & \\
\hline \multirow{2}{*}{1} & (Constant) & 50,628 & 4,030 & & 12,563 &, 000 \\
\cline { 2 - 6 } & Gaya Kepemimpinan &,- 286 &, 117 &,- 263 & $-2,454$ &, 016 \\
\cline { 2 - 6 } & Komunikasi &,- 272 &, 117 &,- 247 & $-2,316$ &, 023 \\
\cline { 2 - 5 } & Stres Kerja &, 167 &, 061 &, 238 & 2,746 &, 007 \\
\hline
\end{tabular}

a. Dependent Variable: Turnover Intention

Sumber: SPSS V 22

Nilai regresi yang diperoleh $Y=50,628-0.286 X_{1}-272 X_{2}+0.167 X_{3}$

\section{Pengaruh gaya kepemimpinan terhadap turnover intention}

Berdasarkan hasil perhitungan regresi berganda, diperoleh nilai regresi sebesar -0,286 (negatif), yang mengindikasikan bahwa jika variabel gaya kepemimpinan $\left(\mathrm{X}_{1}\right)$ meningkat maka intensi turnover 
(Y) akan terus menurun sebesar -0.286. signifikansi $0,016<0,05$ membuktikan Gaya kepemimpinan berpengaruh signifikan terhadap turnover intention (Y).

\section{Pengaruh komunikasi terhadap turnover intention}

Berdasrkan hasil perhitungan regresi berganda diperoleh nilai regresi sebesar $-0,272 \mathrm{X}_{2}$ (negative), nilai ini menunjukan bahwa apabila variabel komunikasi $\left(\mathrm{X}_{2}\right)$ meningkat maka angka turnover intention (Y) akan menurun sebesar -272. signifikansi sebesar 0,023 $<0,05$ membuktikan komunikasi $\left(\mathrm{X}_{2}\right)$ berpengaruh signifikan terhadap angka turnover intention (Y).

\section{Pengaruh stress kerja terhadap turnover intention}

Berdasrkan hasil perhitungan regresi berganda diperoleh nilai regresi sebesar $0,167 \mathrm{X}_{3}$ (positif), nilai ini menunjukan bahwa apabila variabel stress kerja $\left(\mathrm{X}_{3}\right)$ meningkat maka angka turnover intention $(\mathrm{Y})$ akan meningkat sebesar 0,167 satuan. signifikansi $0,07<0,05$ membuktikan bahwa variabel stress kerja $\left(\mathrm{X}_{3}\right)$ berpengaruh signifikan terhadap angka turnover intention (Y).

\section{Uji Hipotesis Simultan}

\section{Tabel}

Uji F

\begin{tabular}{|c|r|r|r|r|r|}
\hline \multicolumn{1}{|c|}{ Model } & $\begin{array}{c}\text { Sum of } \\
\text { Squares }\end{array}$ & df & Mean Square & F & Sig. \\
\hline 1 Regression & 1142,798 & 3 & 380,933 & 11,704 &, $000^{\circ}$ \\
$\begin{array}{l}\text { Residual } \\
\text { Total }\end{array}$ & 3352,398 & 103 & 32,548 & & \\
\hline
\end{tabular}

a. Dependent Variable: Turnover Intention

b. Predictors: (Constant), Stres Kerja, Komunikasi, Gaya Kepemimpinan Sumber: SPSS V 22

Berdasarkan tabel 5 nilai $\mathrm{F}_{\text {hitung }}$ yang lebih tinggi sebesar 11,704 > $F_{\text {tabel }}$ sebesar 3,08 dengan siginifikan $0,000<0,05$ dengan demikian Hipotess nol ditolak dan Hipotesis alternatif diterima, artinya secara simultan adanya pengaruh yang signifikan antara gaya kepemimpinan, komunikasi organisasi dan stress kerja terhadap turnover intention.

\section{E. Hasil Koefisien Determinasi}

Tabel

Koefisien Determinasi

\begin{tabular}{|l|l|r|r|r|}
\hline Model & R & R Square & Adjusted R Square & \multicolumn{2}{|c|}{$\begin{array}{c}\text { Std. Error of the } \\
\text { Estimate }\end{array}$} \\
\hline 1 &, $504^{\mathrm{a}}$ &, 254 &, 233 & 5,705 \\
\hline
\end{tabular}

a. Predictors: (Constant), Stres Kerja, Komunikasi, Gaya Kepemimpinan

b. Dependent Variable: Turnover Intention

Sumber: SPSS V 22

Tabel tersebut menunjukan besarnya kontribusi gaya kepemimpinan, komunikasi dan stress kerja terhadap variabel turnover intention sebesar 25,4\%, sedangkan pengaruh faktor lain sebesar 74,6\%. 


\section{KESIMPULAN DAN SARAN}

\section{A. Kesimpulan}

1. Adanya pengaruh negatif yang signifikan antara gaya kepemimpinan terhadap turnover intention pada PT Pertama Logistics Service hal tersebut memberikan bukti bahwa semakin meningkat gaya kepemimpinan maka angka turnover intention menjadi menurun.

2. Adanya pengaruh negatif yang signifikan antara komunikasi terhadap turnover intention pada PT Pertama Logistics Service hal tersebut memberikan bukti bahwa apabila komunikasi dalam organisasi dapat berjalan dengan baik maka angka turnover intention menjadi menurun.

3. Adanya pengaruh positif yang signifikan antara stres kerja terhadap turnover intention pada PT Pertama Logistics Service hal tersebut memberikan bukti bahwa seorang karyawan yang memiliki stres kerja dalam bekerja maka angka turnover intention akan meningkat.

4. Secara simultan gaya kepemimpinan, komunikasi organisasi, dan stress kerja berpengaruh signifikan terhadap turnover intention pada PT. Pertama Logistics Service. Hal ini dapat dilihat dari nilai Fhitung $11,704>\mathrm{F}_{\text {tabel }} 3,08$ dengan siginifikan $0,000<0,05$.

\section{B. Saran}

Berdasarkan hasil penelitian yang didapatkan maka saran yang ingin penulis sampaikan khususnya pada PT Pertama Logistics Service yaitu:

1. Manajer perlu lebih memperhatikan kebijakan proses yang seharusnya dapat meningkatkan kontrol atas karyawan yang lebih baik, dan memberikan keputusan bersama bawahan.

2. Untuk memudahkan karyawan mendapatkan informasi dari atasan, penulis menyarankan agar atasan harus lebih memperhatikan bawahan mereka yang memasuki kantor dan berinteraksi dengan bawahan, manajer juga harus dapat menjelaskan informasi yang lengkap dan jelas kepada bawahan agar berkinerja dengan baik.

3. Perusahaan sebaiknya memperhatikan pembagian beban kerja secara adil sehingga tidak terjadi kelebihan beban kerja sehingga dapat mengurangi stres kerja karyawan.

4. Untuk mengurangi angka turnover, perusahaan perlu mengevaluasi kebijakan mereka dalam meningkatkan kepuasan kerja karyawan dan mengurangi niat pindah, yang pada gilirannya dapat mengurangi tingkat turnover. Kebijakan kompensasi, peningkatan karir dan promosi yang lebih adil, lebih transparan, dan berdasarkan pada kompetensi dan kinerja bagi semua karyawan untuk meningkatkan kepuasan kerja adalah upaya yang perlu lebih ditekankan dalam kebijakan internal perusahaan untuk mengurangi turnover tinggi saat ini. 


\section{DAFTAR PUSTAKA}

Ardana, 2010, Manajemen Sumber Daya Manusia, Graha Ilmu, Yogyakarta.

Ghozali, 2012, Aplikasi Analisis Multivariate Dengan Program SPSS, Penerbit Universitas Diponegoro, Semarang.

Griffin, 2011, Manajemen, Edisi Ke Tujuh, Erlangga, Jakarta.

Hasibuan, 2012, Manajemen Sumber Daya Manusia. Cetakan Ketujuh Penerbit PT. Bumi Aksara, Jakarta.

Hersey, 2012, Manajemen Perilaku Organisasi : Pendayagunaan Sumber Daya Manusia, Terjemahan Agus Dharma, Erlangga, Jakarta.

Ivancevich, 2012, Perilaku dan Manajemen Organisasi, Jilid 1, Erlangga, Jakarta.

Mangkunegara, 2013, Evaluasi Kerja Sumber Daya Manusia, Penerbit Rafika Aditama, Bandung.

Rivai, 2014, Manajemen Sumber Daya Manusia Untuk Perusahaan dari Teori ke Praktik Edisi 2, Murai Kencana, Jakarta.

Siagian, 2009, Manajemen Sumber Daya Manusia, PT Bumi Aksara, Jakarta. 